\title{
Synthesis and binding properties of peptidomimetics based on a dendritic polymer
}

\author{
Chie Kojima ${ }^{1}$, Harumi Fukada ${ }^{2}$ and Takashi Inui ${ }^{2}$ \\ Dendrimers are attractive polymers with a well-defined structure and multivalent terminal groups. We have designed a novel \\ type of peptidomimetic based on a dendrimer by modifying the amino acids at the periphery of the dendrimer. Alanine- and \\ phenylalanine-bound dendrimers containing different ratios of the two amino acids were synthesized by controlling the reaction \\ ratios. A dendritic peptidomimetic containing proline (Pro) and arginine (Arg) was also synthesized. It has been reported that \\ Pro- and Arg-containing peptides, named Pro-rich peptides, are associated with the src homology 3 (SH3) domain. We have \\ focused on the binding of a Pro-rich peptide of dynamin to the SH3 domain of amphiphysin II as a model case of protein- \\ protein interaction. The dendritic peptidomimetic containing Pro and Arg was found to bind to the SH3 domain to a similar \\ degree as the dynamin Pro-rich peptide, indicating that dendrimers conjugating amino acids can behave as potential \\ peptidomimetics.
}

Polymer Journal (2013) 45, 339-345; doi:10.1038/pj.2012.141; published online 11 July 2012

Keywords: dendrimer; peptide library; peptidomimetics; protein-protein interaction

\section{INTRODUCTION}

Combinatorial peptide libraries are useful tools for elucidating protein interactions in the design of new drugs and can also facilitate the development of a greater understanding of biological physiology and pathophysiology. Combinatorial peptide libraries, which have been designed using solid-phase peptide synthesis, have classically been used to identify bioactive peptides. ${ }^{1,2}$ There are, however, two major difficulties associated with synthetic peptide libraries, in that the synthesis of diverse peptides can be challenging ${ }^{1-3}$ and short peptides exhibit low levels of affinity because of their overall structural flexibility. ${ }^{4,5}$

In contrast to linear polymers, dendritic polymers possess highly controllable sizes, topologies and surface properties. A variety of novel functional materials based on dendrimers have been developed for a variety of biological applications, ${ }^{6}$ with examples including candidate drugs, tissue repair scaffolds, targeted carriers of chemotherapeutics and sensors. ${ }^{7-13}$ One of the major advantages associated with using dendritic polymers is their ability to modify and cluster bioactive molecules at the periphery of their structures, including drugs, peptides and sugars. The clustering effect of dendritic polymers is useful for multiple binding interactions, in that biomacromolecules can interact with each other with a high degree of selectivity and potent levels of affinity because of multivalent bonding. ${ }^{14-18}$ For example, multi-antigen peptides (dendrimers with antigen peptides at the periphery) have been successfully used in a practical setting to efficiently raise antibodies. ${ }^{14}$ Furthermore, peptides attached to dendrimers at the periphery have been reported to bind to target proteins with a slow dissociation rate. ${ }^{15}$ Dendrimers with a sugar moiety at the periphery have also been produced to interact with and recognize the surfaces of cells. ${ }^{16-18}$ In contrast to the multivalency of a single small molecule, the ability of dendrimers to accept multiple dense and multifunctional terminal groups provides extensive additional benefits, including the potential for a variety of chemical reactions and a controllable conformation..$^{7-13,19}$ The clustering of some collagen model peptides at the periphery of dendrimers has also been reported to induce the formation of higher-order structures. ${ }^{20-24}$ Furthermore, the mobility of the terminal groups in these dendrimers was found to be restricted as a consequence of steric hindrance. ${ }^{14-24}$ This property is crucial for the improvement of chemical interactions because the preparation of conformationally restricted peptides, such as intramolecular circularized peptides and peptides incorporating stable $\alpha$ helix and $\beta$ turn motifs, can enhance the affinity. 4,5

In this study, we have successfully designed dendritic polymers that have been modified with various acetylated amino acids at the periphery, termed dendritic peptidomimetics, for application in a peptide-mimic library. The dendron core was modified with detection modules, including a fluorescent dye and biotin, to allow for the peptidomimetic to be detected (Figure 1). Compounds of this type are often candidates for application in synthetic peptide libraries

\footnotetext{
${ }^{1}$ Nanoscience and Nanotechnology Research Center, Research Organization for the 21st Century, Osaka Prefecture University, Osaka, Japan and ${ }^{2}$ Division of Applied Life Science, Graduate School of Life and Environmental Sciences, Osaka Prefecture University, Osaka, Japan

Correspondence: Dr C Kojima, Nanoscience and Nanotechnology Research Center, Research Organization for the 21st Century, Osaka Prefecture University, 1-2 Gakuen-cho, Naka-ku, Sakai, Osaka 599-8570, Japan.

E-mail: c-kojima@21c.osakafu-u.ac.jp

Received 12 March 2012; revised and accepted 5 June 2012; published online 11 July 2012
} 


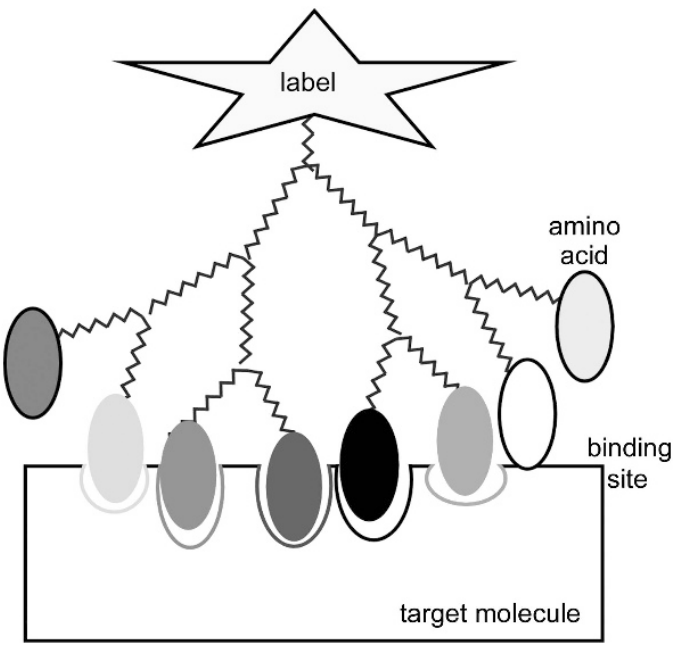

Figure 1 Design of peptidomimetics based on dendritic polymer. A full color version of this figure is available at Polymer Journal online.

because a virtually one-step synthesis using the 20 different natural amino acids can enable the preparation of a variety of peptidomimetics. For example, the reaction of the eight terminal groups from generation 3 (G3) of a dendron with 20 amino acids would yield a library of $8^{20}\left(2.56 \times 10^{10}\right)$ peptides, representing a number much greater than what could be achieved with a conventional synthetic peptide library, which is similar to that encountered in a phagedisplay peptide library. Although it is difficult to exert any control over the configuration of each amino acid in the compound, peptidomimetics of this type may be useful screening tools for determining which amino acids provide important binding interactions. In the current study, we have successfully synthesized polyamidoamine (PAMAM) dendrons, which have been conjugated with different ratios of alanine (Ala) and phenylalanine (Phe) as model peptidomimetics. The binding properties of the resulting dendronbased peptidomimetics were subsequently investigated with particular focus on their interaction with amphiphysin II, which is a wellestablished adaptor protein. The src homology 3 (SH3) domain of amphiphysin II has been reported to interact with proline (Pro)-rich peptides (PxxPxR). ${ }^{25-27}$ With this in mind, we synthesized Pro (P)and arginine (Arg, R)-conjugated PAMAM dendrons. A fluorescent nitrobenzoxadiazole (NBD) dye was also incorporated into the product to produce a fluorescent Pro-rich dendritic peptidomimetic. The binding experiments to the amphiphysin II SH3 domain were performed by the pull-down assay and the thermodynamic binding parameters were estimated from isothermal titration calorimetry (ITC) analysis, with the results being compared with those of a Pro-rich peptide-binding motif of dynamin.

\section{EXPERIMENTAL PROCEDURE}

\section{Materials}

L-Phe, L-Ala, L-Pro, triethylamine (TEA), trifluoroacetic acid (TFA), thioanisol and trifluoromethanesulfonic acid were purchased from Kishida Chemical (Osaka, Japan). $N$-((tert-butoxy)carbonyl)-Arg with a tosyl (Tos)-protected side chain (Boc-Arg(Tos)) was purchased from Peptide Institute (Osaka, Japan). $N$-hydroxysuccinimide, 1,3-dicyclohexycarbodiimide, and NBD chloride (NBD-Cl) were obtained from Tokyo Kasei Kogyo (Tokyo, Japan). Bocprotected PAMAM dendron (G3) was synthesized according to the previous report. ${ }^{28}$ A dynamin peptide (QVPSRPNRAP) was obtained from Toray Research Center, Inc. (Tokyo, Japan).

\section{Characterization}

All products were characterized by ${ }^{1} \mathrm{H}$ and ${ }^{13} \mathrm{C}$ nuclear magnetic resonance (NMR) (JEOL Ltd., Tokyo, Japan, $400 \mathrm{MHz}$ ) using $\mathrm{D}_{2} \mathrm{O}$ as the solvent containing 3-(trimethylsilyl) propionic acid- $\mathrm{d}_{4}$ sodium salt. High-performance liquid chromatography analysis was conducted on an high-performance liquid chromatography system equipped with a Cosmosil 5C18-MS-II packed column (Nacalai Tesque, Inc., Kyoto, Japan) and a UV detector $(210 \mathrm{~nm}$; UV-2075Plus; Jasco Inc., Tokyo, Japan). Samples were injected and eluted at a rate of $1.0 \mathrm{ml} \mathrm{min}^{-1}$ using a PU-2089Plus pump (Jasco Inc.) with a $20 \mathrm{~mm}$ phosphate buffer ( $\mathrm{pH} 2.5$ ) containing $10 \%$ methanol (A) and acetonitrile (B). A linear gradient elution was performed over a period of $30 \mathrm{~min}$ from an initial state of $100 \%$ (A) to a final state of $10 \%$ (A) with $90 \%$ (B).

\section{Synthesis of acetylated amino acids}

Acetylated Ala (Ac-Ala), acetylated Phe (Ac-Phe) and acetylated Pro (Ac-Pro) were synthesized according to the following representative example involving L-Phe. L-Phe $(1.2 \mathrm{~g})$ was dissolved in $4 \mathrm{M}$ aqueous solution of $\mathrm{NaOH}$ on ice More than 10 molar equivalents of both acetic anhydride and $4 \mathrm{~m}$ aqueous solution of $\mathrm{NaOH}$ were then added simultaneously to the solution in a dropwise manner so as to maintain the $\mathrm{pH}$ of the solution in the range 9.5-11.5 Upon completion of the addition, the mixture was stirred overnight at $4{ }^{\circ} \mathrm{C}$. The $\mathrm{pH}$ of the reaction mixture was then adjusted to 2.5 by the addition of a $6 \mathrm{~N}$ solution of aqueous $\mathrm{HCl}^{22}$ The resulting mixture was extracted with ethyl acetate. The product was subsequently precipitated from the ethyl acetate solution via the addition of hexane to give the desired product $(1.2 \mathrm{~g}, 77 \%$ yield). L-alanine $(5.5 \mathrm{~g}$ ) and L-Pro $(1.15 \mathrm{~g})$ provided the corresponding acetylated products Ac-Ala and Ac-Pro in yields of $54 \%$ and $39 \%$, respectively. ${ }^{1} \mathrm{H}$ NMR $\left(\mathrm{D}_{2} \mathrm{O}\right)$ for Ac-Ala: $\delta 1.39(\mathrm{~d}, \mathrm{H} \beta), 2.01\left(\mathrm{~s}, \mathrm{CH}_{3} \mathrm{CO}\right)$ and $4.29(\mathrm{q}, \mathrm{H} \alpha) \cdot{ }^{13} \mathrm{C}$ NMR $\left(\mathrm{D}_{2} \mathrm{O}\right)$ for Ac-Ala: $\delta 19.3(\mathrm{C} \beta), 24.6\left(\mathrm{CH}_{3} \mathrm{CO}\right)$, $52.1(\mathrm{C} \alpha)$ and $176.9(\mathrm{CO}) .{ }^{1} \mathrm{H}$ NMR $\left(\mathrm{D}_{2} \mathrm{O}\right)$ for Ac-Phe: $\delta 1.91\left(\mathrm{~s}, \mathrm{CH}_{3} \mathrm{CO}\right)$, 2.92 and $3.19(\mathrm{~m}, \mathrm{H} \beta), 4.46(\mathrm{~m}, \mathrm{H} \alpha)$, and 7.29 and $7.36\left(\mathrm{~m}\right.$, phenyl). ${ }^{13} \mathrm{C}$ NMR $\left(\mathrm{D}_{2} \mathrm{O}\right)$ for Ac-Phe: $\delta 24.7\left(\mathrm{CH}_{3} \mathrm{CO}\right), 40.5(\mathrm{C} \beta), 59.1(\mathrm{C} \alpha), 129.8,131.5$, 132.2, 140.7 (phenyl) and $176.3(\mathrm{CO}) .{ }^{1} \mathrm{H}$ NMR $\left(\mathrm{D}_{2} \mathrm{O}\right)$ for Ac-Pro: $\delta 1.99$ and $2.33(\mathrm{~m}, \mathrm{H} \beta$ and $\mathrm{H} \gamma), 2.11\left(\mathrm{~s}, \mathrm{CH}_{3} \mathrm{CO}\right), 3.46$ and $3.62(\mathrm{~m}, \mathrm{H} \delta)$, and 4.39 and $4.51(\mathrm{~m}, \mathrm{H} \alpha) .{ }^{13} \mathrm{C}$ NMR $\left(\mathrm{D}_{2} \mathrm{O}\right)$ for Ac-Pro: $\delta 24.2\left(\mathrm{CH}_{3} \mathrm{CO}\right), 25.5$ and 27.2 $(\mathrm{C} \gamma), 32.4$ and $34.0(\mathrm{C} \beta), 49.8$ and $51.4(\mathrm{C} \delta), 62.2(\mathrm{C} \alpha)$ and $175.9(\mathrm{CO})$.

Acetylated Arg with an $N$-Tos-protected side chain (Ac-Arg(Tos)) was synthesized according to the following procedure. Boc-Arg(Tos) $(1.0 \mathrm{~g})$ was treated with TFA $(5 \mathrm{ml})$ on ice. Following a 4 -h hold period, the mixture was evaporated to dryness and the resulting residue was dissolved in $4 \mathrm{M}$ aqueous solution of $\mathrm{NaOH}$ on ice. More than 10 molar equivalents of acetic anhydride and $4 \mathrm{~m}$ aqueous solution of $\mathrm{NaOH}$ were added simultaneously to the solution with cooling in a drop-wise manner so as to maintain the $\mathrm{pH}$ of the mixture in the range 9.5-11.5. Upon completion of the addition, the mixture was stirred overnight at $4{ }^{\circ} \mathrm{C}$. An aqueous solution $(6 \mathrm{~N})$ of $\mathrm{HCl}$ was then added to adjust the $\mathrm{pH}$ of the mixture to 2.5 . The aqueous mixture was then extracted with ethyl acetate. The organics were then collected and evaporated to dryness to give the crude product, which was recrystallized from a $\mathrm{CH}_{3} \mathrm{Cl} /$ methanol $(\mathrm{MeOH}) /$ ether mixture to give the desired product $\mathrm{Ac}$ $\operatorname{Arg}(\mathrm{Tos})$ (yield of 50\%). ${ }^{1} \mathrm{H}$ NMR $\left(\mathrm{D}_{2} \mathrm{O}\right)$ for $\mathrm{Ac}-\operatorname{Arg}(\mathrm{Tos}): \delta 1.49$ (m, $\mathrm{H} \gamma$ ),

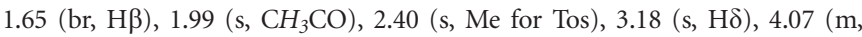
$\mathrm{H} \alpha$ ) and 7.40 and 7.75 (d, phenyl for Tos). ${ }^{13} \mathrm{C}$ NMR $\left(\mathrm{D}_{2} \mathrm{O}\right)$ for $\mathrm{Ac}-\operatorname{Arg}(\mathrm{Tos}): \delta$ 23.3, 23.5, 24.6 (Cy or Me for Tos), $24.4\left(\mathrm{CH}_{3} \mathrm{CO}\right), 30.9(\mathrm{C} \beta), 56.4(\mathrm{C} \delta), 58.1$ (C $\alpha), 128.5,128.8,132.4,132.7,146.8$ and 159.9 (phenyl for Tos), 176.6 (CO) and $179.9(\mathrm{CN})$.

Synthesis of fluorescent dendron-based peptidomimetics with Ala and Phe

The acetylated amino acids (total $0.20 \mathrm{mmol}$ ) with different Ala percentages in total amino acids $(0,10,30,50,70,90$ and $100 \mathrm{~mol} \%), N$-hydroxysuccinimide $(0.24 \mathrm{mmol}), 1,3$-dicyclohexycarbodiimide $(0.26 \mathrm{mmol})$ and TEA $(0.30 \mathrm{mmol})$ were mixed together in distilled $N, N$-dimethyl formamide and stirred for $4 \mathrm{~h}$ in an ice-bath. A solution of the G3 Boc-PAMAM dendrons $(30 \mathrm{mg})$ in distilled dimethyl sulfoxide was then added and the resulting mixture was stirred for 2 days at room temperature. The desired Boc-PAMAM dendrons attached to 
acetylated amino acids were then purified using a Sephadex LH-20 column (GE Healthcare UK Ltd., Buckinghamshire, UK) with $\mathrm{MeOH}$ as the eluent. ${ }^{29}$

The Boc-PAMAM dendrons attached to the acetylated amino acids were treated with TFA $(2 \mathrm{ml})$ with cooling in an ice-bath and the resulting mixture was stirred for $4 \mathrm{~h}$ to remove the Boc groups. Following the 4-h hold period, the reaction mixture was evaporated to dryness and the residue was dissolved in an excess of TEA and subsequently precipitated by the addition of $\mathrm{MeOH}$ and ether. The solids were collected and subsequently dissolved in ethanol and an excess of NBD-Cl was added. The resulting mixture was stirred for $1 \mathrm{~h}$ before being evaporated to dryness and purified using a Sephadex LH-20 column to give the desired NBD-labeled PAMAM dendrons attached to Ac-Ala and Ac-Phe with Ala percentages of 100, 90, 70, 50, 30, 10 and $0 \%$ in yields of $69 \%, 33 \%, 65 \%, 57 \%, 54 \%, 47 \%$ and $55 \%$, respectively, from the starting materials.

\section{Synthesis of fluorescent dendron-based peptidomimetics with Pro and Arg}

Ac-Pro $(0.51 \mathrm{mmol})$ and $\mathrm{Ac}-\mathrm{Arg}(\mathrm{Tos})(0.17 \mathrm{mmol})$ were both reacted with $N$-hydroxysuccinimide $(0.82 \mathrm{mmol}), 1,3$-dicyclohexycarbodiimide $(0.89 \mathrm{mmol})$ and TEA $(1.03 \mathrm{mmol})$ in distilled $N, N$-dimethyl formamide for $5 \mathrm{~h}$ with cooling in an ice-bath. A solution of the G3 Boc-PAMAM dendrons (100 mg) in distilled dimethyl sulfoxide was then added and the resulting mixture was stirred for 2 days at room temperature. The mixture was purified using a Sephadex LH-20 column with $\mathrm{MeOH}$ as the eluent to afford the desired product in a $75 \%$ yield.

The Boc-PAMAM dendrons with $\operatorname{Pro} / \operatorname{Arg}(T o s)$ were treated with TFA $(2 \mathrm{ml})$ with cooling in an ice-bath and the resulting mixture was stirred for $3 \mathrm{~h}$ to remove the Boc groups. The mixture was evaporated to dryness and the resulting residue was dissolved in TEA $(3 \mathrm{ml})$ and subsequently precipitated with $\mathrm{MeOH}$, ether and hexane. The solid residues were collected and dissolved in ethanol and treated with an excess of NBD-Cl. The resulting mixture was stirred for $1 \mathrm{~h}$ before being evaporated to dryness and purified using a Sephadex LH-20 column. The resulting residue was dissolved in TFA, and thioanisol (10 eq. to thioanisol and trifluoromethanesulfonic acid) and thioanisol and trifluoromethanesulfonic acid (0.1 eq. to TFA) were added sequentially. ${ }^{30}$ The reaction mixture was stirred for $8 \mathrm{~h}$ at room temperature before ether was added to facilitate the precipitation of the reaction product. The solid was collected and dissolved in a mixture of $\mathrm{MeOH}$ and TEA, and subsequently purified using a Sephadex LH-20 column. The purified compound was then dialyzed and freeze-dried to give the desired product in a $62 \%$ yield.

\section{Preparation of amphiphysin II SH3 domain}

The Binl (amphiphysin II) SH3 domain (amino acids 374-454) was cloned into pGEX-6P-1, to be fused in frame to the $\mathrm{COOH}$-terminus of glutathione S-transferase (GST) and expressed in Escherichia coli. ${ }^{27}$ The GST-SH3 domain and the isolated GST were purified using glutathione beads (GE Healthcare UK Ltd.), and subsequently used for the pull-down assay. The proteins bound to the glutathione beads were then incubated with PreScission Protease (GE Healthcare UK Ltd.) at $4{ }^{\circ} \mathrm{C}$ for $6 \mathrm{~h}$ to allow for cleavage of the GST tag. The purity was estimated by sodium dodecyl sulfate-polyacrylamide gel electrophoresis with Coomassie brilliant blue staining ${ }^{27}$ to be $>90 \%$.

\section{Pull-down assay}

The fluorescent dendritic peptidomimetics $(500 \mathrm{nmol})$ were mixed with GST fusion proteins $(2.5 \mathrm{nmol})$ (GST-SH3 domain and GST alone) bound to glutathione beads in a $1 \%$ NP-40 buffer (1\% Nonidet P- $40,150 \mathrm{~mm} \mathrm{NaCl}$, $20 \mathrm{~mm}$ Tris- $\mathrm{HCl}$, pH 7.4 and $5 \mathrm{~mm}$ EDTA). Following an overnight incubation at $4{ }^{\circ} \mathrm{C}$, the glutathione beads were washed with a $1 \% \mathrm{NP}-40$ buffer $^{27}$ and then treated with a HBST buffer (20 mм Hepes (pH 7.4), $150 \mathrm{~mm} \mathrm{NaCl}, 5$ mм EDTA and $0.005 \%$ Tween 20 ) containing $50 \%$ acetic acid to remove the dendritic peptidomimetics from the beads. Following centrifugation, the fluorescence intensity of the supernatant was measured $\left(\lambda_{\mathrm{ex}}=450 \mathrm{~nm}\right.$ and $\left.\lambda_{\mathrm{em}}=530 \mathrm{~nm}\right)$. The binding percentage was calculated from the ratio of fluorescence intensity of the supernatant to that of the initial dendritic peptidomimetic solution. The ratios of GST-SH3 binding to the isolated GST binding were estimated. ${ }^{27}$

\section{ITC}

Calorimetric experiments were performed using a VP-ITC instrument (MicroCal Inc., Northampton, MA, USA). The Pro- and Arg-bound dendriticmimetic $(23 \mathrm{~mm})$, Ala-bound dendriticmimetic $(13 \mathrm{~mm})$ or dynamin Pro-rich peptide $(8.9 \mathrm{mM})$ was taken in a syringe and titrated in sequential injections $(10 \mu \mathrm{l}$ each) into an SH3 domain solution (112 $\mu \mathrm{M}$ for peptidomimetics or $57 \mu \mathrm{M}$ for dynamin peptide) at $25^{\circ} \mathrm{C}$. The solution was buffered with Tris- $\mathrm{HCl}$ buffer $(20 \mathrm{~mm})$ containing $0.15 \mathrm{M} \mathrm{NaCl}$ at $\mathrm{pH}$ 7.4. The thermodynamic parameters were determined using a one-site-binding model supplied by MicroCal Origin software. ${ }^{31}$ In this calculation, the binding stoichiometry $(n)$ was fixed at a value of 1 . Heats of dilution were subtracted from the isotherms prior to fitting.

\section{RESULTS AND DISCUSSION}

\section{Synthesis of the Ala/Phe-bound dendrons}

The peptidomimetics based on a dendron with Ala and Phe were synthesized as shown in Figure 2. The Boc-protected PAMAM dendron of G3 was synthesized according to a previously reported method. ${ }^{28}$ The eight terminal amino groups of the PAMAM dendron were reacted in different ratios with Ac-Ala and Ac-Phe according to our previously published procedure. ${ }^{29}$ These compounds were characterized by ${ }^{1} \mathrm{H} \mathrm{NMR}$, as shown in Figure $3 \mathrm{a}$. The binding numbers of amino acids to the dendron were estimated from the integral ratios of the amino acids (Ala, 4.2 p.p.m.; Phe, 4.5 p.p.m.) to the Boc group of the PAMAM dendron (1.4 p.p.m.), as listed in Table 1 . These results demonstrated that essentially every terminal amino group was attached to an Ala or Phe. The bound ratios of amino acids to the dendron were essentially equal to the mixing ratio from the reaction, suggesting that the variety of peptides in the library could be controlled by regulating the mixing ratios of the amino acids. NBD-Cl was subsequently reacted with the core of the dendron following a Boc-deprotection process. Characterization by ${ }^{1} \mathrm{H}$ NMR (Figure $3 \mathrm{~b}$ ) revealed that the Boc group at 1.4 p.p.m. had disappeared, whereas a peak corresponding to the NBD moiety had emerged at 7.2 p.p.m., indicating that the NBD-labeled dendritic peptidomimetics had been successfully obtained.

These compounds were also analyzed using high-performance liquid chromatography. Figure 4 shows that the dendrons functionalized with Ala or Phe at all of the termini were eluted over a range of 9.1-17.1 min depending on the Ala ratio, with a greater Ala ratio corresponding to a shorter retention time. The Ala/Phe-dendron containing $90 \%$ Ala exhibited peaks at 9.1 and $10.9 \mathrm{~min}$, which were attributed to the Ala/Phe-attached dendrons with ratios of $8 / 0$ and $7 / 1$, respectively. The $70 \%$ Ala dendron provided peaks at 9.1, 10.9, 12.2 and $13.6 \mathrm{~min}$, which were attributed to the Ala/Phe-attached dendrons with ratios of $8 / 0,7 / 1,6 / 2$ and $5 / 3$, respectively. Peaks with retention times $>13.6 \mathrm{~min}$ could not clearly be detected because of peak broadening. Taken together, the NMR and high-performance liquid chromatography results indicated that peptidomimetics composed of various members could be synthesized, with average ratios corresponding well with the mixing ratios. Thus, our system can produce a diverse library from the same reaction ratio.

Binding properties of dendritic peptidomimetics in a model system It has been reported that there are numbers of protein-protein interactions in signal transduction. A series of proteins known as adaptor proteins are very important in signal transduction because they have important roles in the recruitment of some functional proteins at the target site and effectively perform this recruitment process in a timed manner. Many adaptor proteins contain SH3 domains, which are known to be bound to Pro-rich sequences 

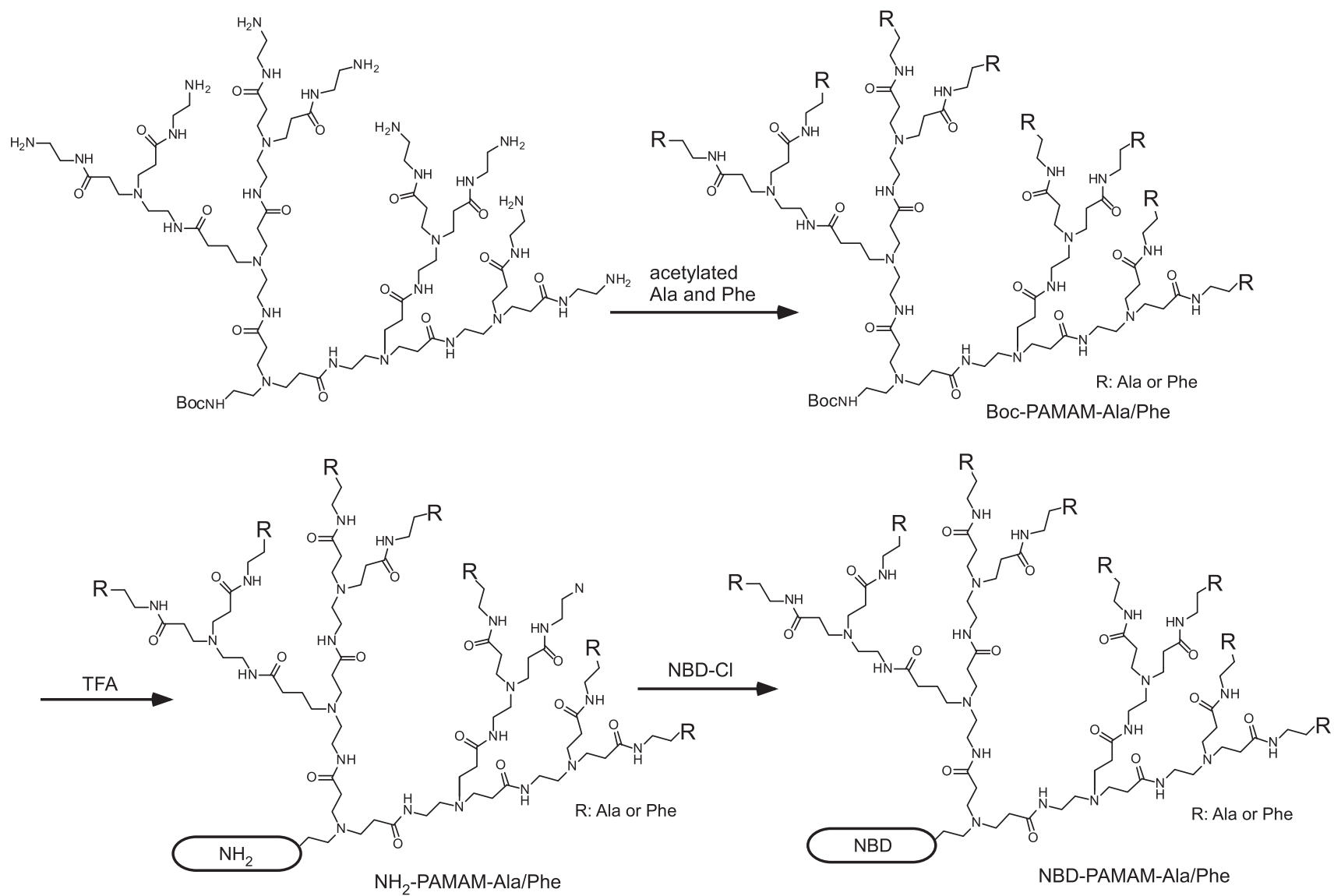

Figure 2 Synthesis of fluorescence-labeled peptidomimetic with Ala/Phe.

a

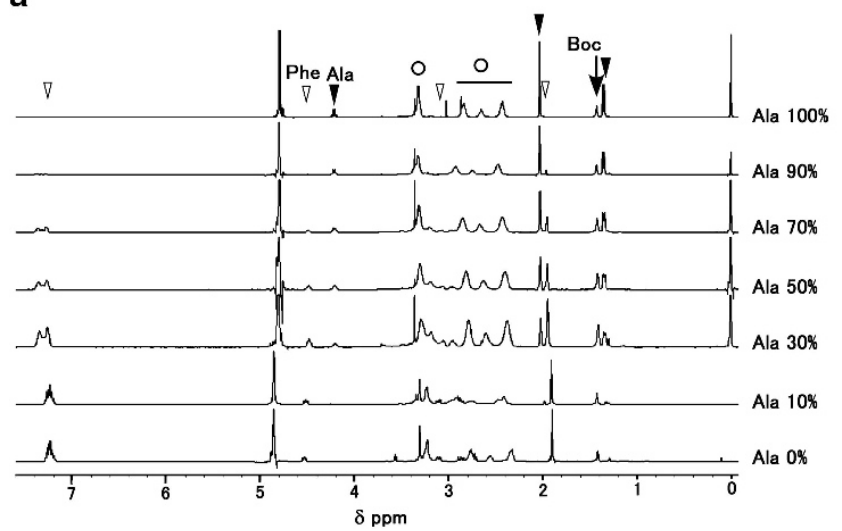

b

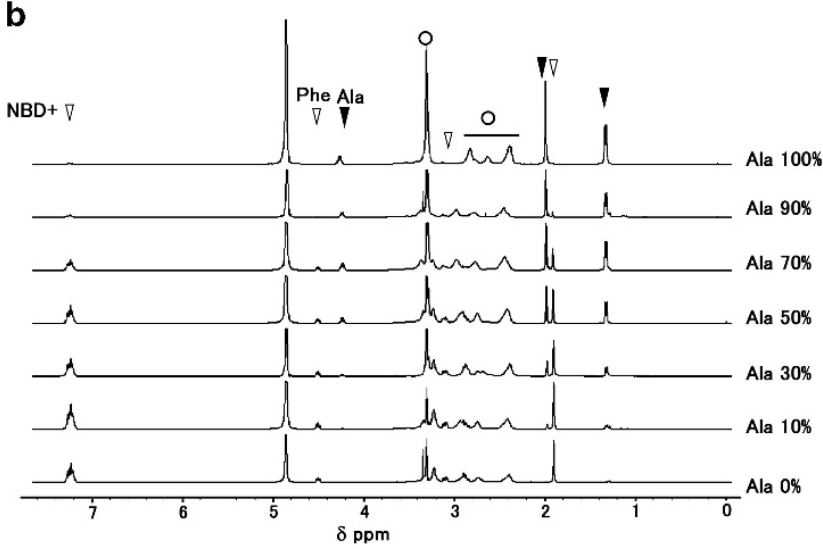

Figure $3{ }^{1} \mathrm{H}$ NMR spectra of Boc-protected (a) and NBD-labeled (b) PAMAM dendrons, which were modified with Ac-Ala and Ac-Phe, at the various Ala percentages of 100,90,70,50,30, 10 and $0 \%$ in $\mathrm{D}_{2} \mathrm{O}$ (a) and $\mathrm{CD}_{3} \mathrm{OD}$ (b). A peak of residual methanol was observed at 3.3 p.p.m. and used as a reference. Peaks marked by circle, open triangle and closed triangle were derived from the PAMAM dendron, Phe and Ala, respectively.

including PxxPxR. ${ }^{26}$ In this study, we focused on the interaction between the amphiphysin II SH3 domain and a Pro-rich peptide of dynamin as a model system. ${ }^{25-27}$ We synthesized Pro (P)- and Arg (R)-conjugated PAMAM dendrons with a Pro/Arg ratio of $3 / 1$ using an NBD core to produce a fluorescent Pro-rich peptidomimetic. The synthesis of these compounds is shown in Figure 5. The PAMAM dendron (G3) was reacted with Ac-Pro and Ac-Arg(Tos) with a Pro/Arg ratio of $6 / 2 .{ }^{29}$ The binding numbers of amino acids to the dendron were estimated from the ${ }^{1} \mathrm{H}$ NMR spectra of the compound using the integral ratios of the amino acids (Pro, 4.14 and 4.30 p.p.m.; Arg, 3.95 p.p.m.), indicating that the ratio of Pro/Arg was 6.7/1.3 (Figure 6a). Subsequent Boc deprotection was performed according to the standard procedures, and the signal corresponding to the Boc group at 1.4 p.p.m. was observed to disappear in the NMR spectrum (Figure 6b). The resulting amino group of the dendron core was then reacted with NBD-Cl followed by removal of the Tos-protecting group in the Arg side chain. ${ }^{30}$ The resulting compound was characterized by NMR spectroscopy (Figure 6c). The spectrum 


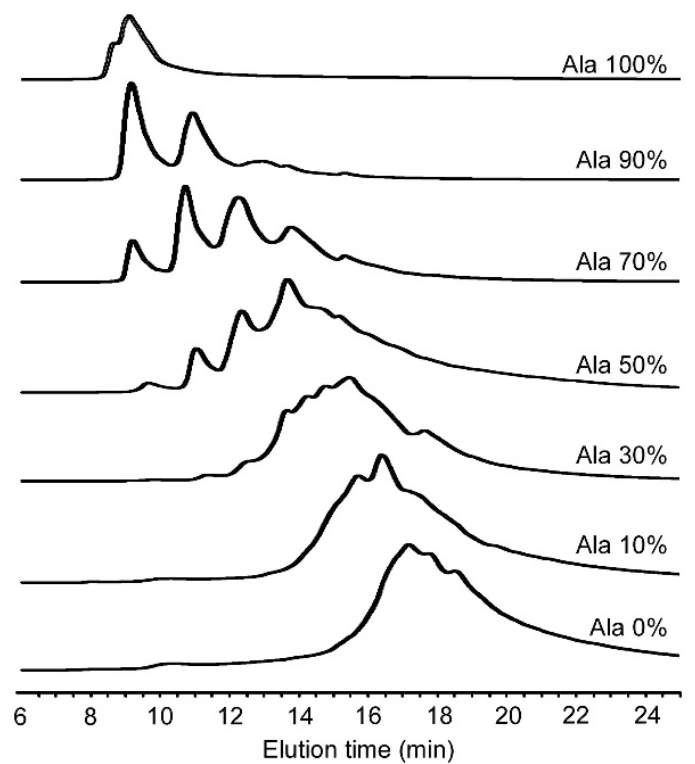

Table 1 Binding numbers of Ala/Phe to dendrons determined by ${ }^{1}$ H NMR

\begin{tabular}{llllc}
\hline \multirow{2}{*}{$\begin{array}{l}\text { Reaction } \\
\text { Ala percentage (\%) }\end{array}$} & Ala & Phe & Tota & Ala percentage (\%) \\
\cline { 2 - 5 } 100 & 8.3 & 0 & 8.3 & 100 \\
90 & 7.2 & 0.6 & 7.8 & 92 \\
70 & 5.8 & 2.4 & 8.2 & 71 \\
50 & 4.0 & 3.9 & 7.9 & 51 \\
30 & 2.8 & 6.0 & 8.8 & 32 \\
10 & 0.7 & 6.7 & 7.4 & 9 \\
0 & 0 & 8.6 & 8.6 & 0 \\
\hline
\end{tabular}

Abbreviations: Ala, alanine; Phe, phenylalanine; NMR, nuclear magnetic resonance. aNumber of the terminal group of generation $3(\mathrm{G} 3)$ is 8 .

Figure 4 High-performance liquid chromatography profiles of Ala/Pheattached dendrons at various percentages.

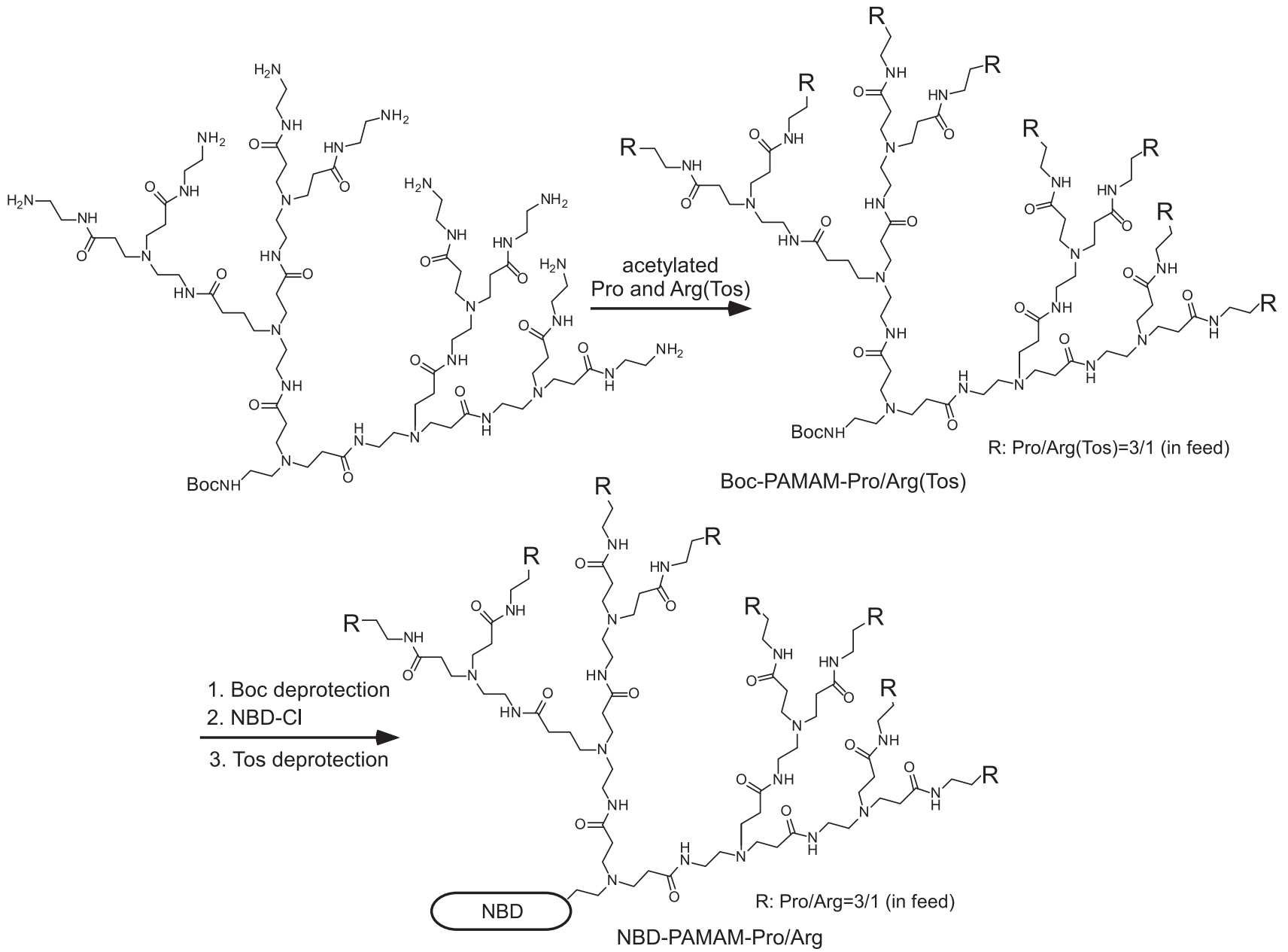

Figure 5 Synthesis of fluorescence-labeled peptidomimetic with Pro/Arg. 


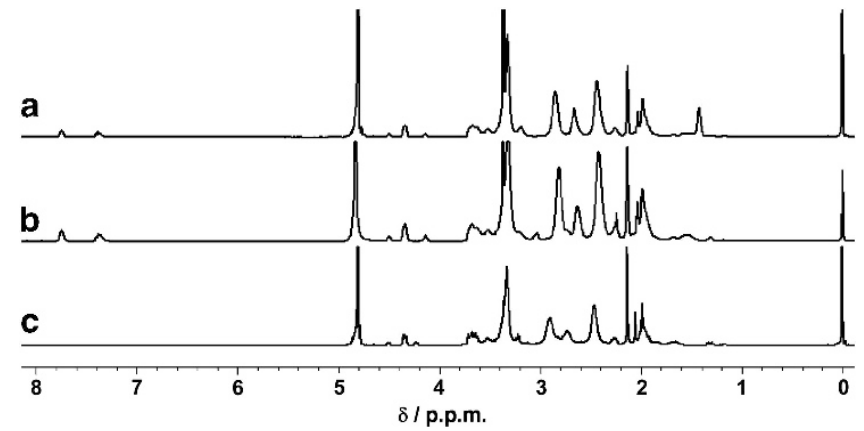

Figure $6{ }^{1} \mathrm{H}$ NMR spectra of Pro/Arg-PAMAM dendrons in $\mathrm{D}_{2} \mathrm{O}$ containing 3-(trimethylsilyl) propionic acid- $\mathrm{d}_{4}$ sodium salt. (a) Pro/Arg(Tos)-PAMAM dendron with Boc core, (b) Pro/Arg(Tos)-PAMAM dendron (Boc deprotection) and (c) NBD-labeled Pro/Arg-PAMAM dendron. NBD signals were not obtained under our condition, because NBD might be fully covered with dendron.

revealed the disappearance of the signals corresponding to the Tos group at 7.4 and 7.8 p.p.m., indicating that the dendritic peptidomimetic with Pro and Arg had been successfully obtained for application in the binding assay to the $\mathrm{SH} 3$ domain. The amphiphysin II SH3 domain was prepared from transformed E. coli according to procedures described in our previous report. ${ }^{27}$

The binding assay of the peptidomimetics to the amphiphysin II SH3 domain was performed using a pull-down assay. Solutions containing the target molecules were mixed with the GST-fused amphiphysin II SH3 domain immobilized on the glutathione beads, with the bound molecules becoming attached to the beads. Therefore, the bound dendritic peptidomimetics with fluorescence label were pulled down. The bound peptidomimetics were subsequently removed from the beads to estimate the degree of association by measuring the fluorescence intensity. To avoid the nonspecific interaction of the peptidomimetics with GST and the beads, control experiments were also performed using GST immobilized on the beads, and the binding ratio of GST-SH3/GST was calculated. The value of the Pro/Arg-bound dendritic peptidomimetic was 1.18, suggesting that the dendritic peptidomimetic was more associated with the amphiphysin II SH3 domain than with the GST region. It was reported that the amphiphysin II SH3 domain was bound to a Pro-rich sequence, but not to alanine peptides. ${ }^{27}$ The pull-down assay using the Ala-bound dendritic peptidomimetic was also performed as a negative control. The binding ratio of GST-SH3/ GST on the Ala-bound dendritic peptidomimetic was 1.39. This suggested that the binding affinities of the Pro/Arg-bound and Alabound dendritic peptidomimetics to the $\mathrm{SH} 3$ domain were similar. The amphiphysin SH3 domain contains not only a hydrophobic pocket to bind to the Pro-rich peptides but also contains an anionic pocket to bind to cationic peptides (RKKSKLFSRLRRKKN). ${ }^{27}$ The peptidomimetics are composed of numbers of tertiary amines at the PAMAM dendrimer and it is possible that the dendron-based peptidomimetics could interact with anionic site of the target protein instead of the binding site to the Pro-rich peptide. The pull-down assay also suggested that the binding affinity was very weak. ITC experiments were also conducted to investigate the binding properties of the peptidomimetics to the amphiphysin II SH3 domain in greater detail. Figure 7 shows the ITC binding curve of the dendron-based peptidomimetic with Pro/Arg to the amphiphysin II SH3 domain. Binding experiments were also performed using the dynamin Pro-rich peptide (QVPSRPNRAP) as a positive control and
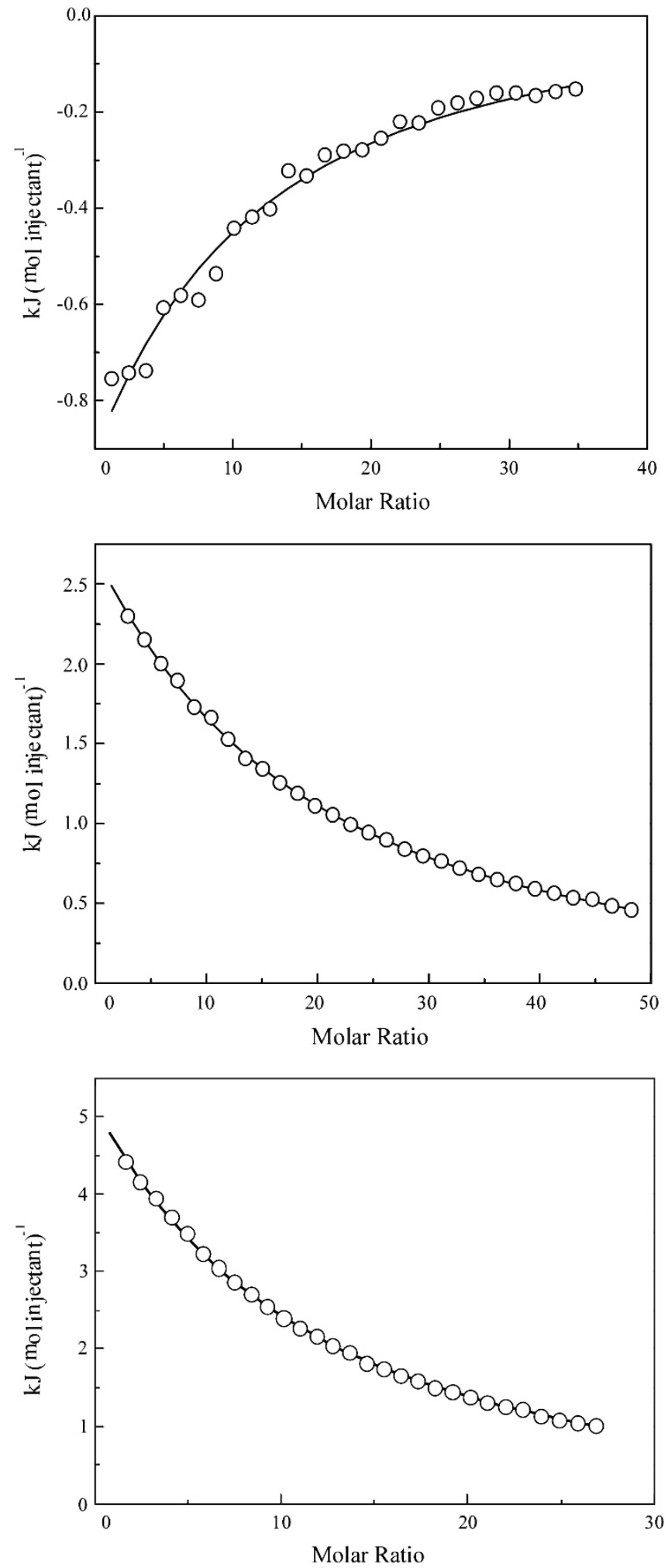

Figure 7 ITC-fitting curve of dynamin peptide (top) and the dendritic peptidomimetics with Pro/Arg (middle) and Ala (bottom).

the dendritic peptidomimetic with Ala as a negative control (Figure 7). A fitting curve against each binding experiment was obtained to estimate the thermodynamic binding parameters, as listed in Table 2. The values obtained in this way were valuable because the 
Table 2 Thermodynamic binding parameters of the dendritic peptidomimetics and control dynamic proline-rich peptide to amphiphysin II SH3 domain

\begin{tabular}{lccc}
\hline Sample & $\mathrm{K}_{d}(\mathrm{~mm})$ & $\Delta \mathrm{H}\left(\mathrm{kJ} \mathrm{mol}^{-1}\right)$ & $\Delta \mathrm{S}\left(\mathrm{J} \mathrm{K} \mathrm{mol}^{-1}\right)$ \\
\hline Dynamin peptide & $1.51 \pm 0.08$ & $-23.9 \pm 0.8$ & $-26.0 \pm 2.8$ \\
Pro/Arg-dendritic peptidomimetic & $4.72 \pm 0.04$ & $113 \pm 0.6$ & $422 \pm 2$ \\
Ala-dendritic peptidomimetic & $2.91 \pm 0.02$ & $134 \pm 0.7$ & $499 \pm 2$ \\
\hline
\end{tabular}

Abbreviations: Ala, alanine; Pro, proline; SH3, src homology 3.

corresponding curves were fitted to the experimental plots using a one-site model. The dissociation constant $\left(K_{\mathrm{d}}\right)$ of the dendron-based peptidomimetic was similar to that of the dynamin Pro-rich peptide, suggesting that the dendron-based compound is a potential peptidomimetic. However, the Ala-conjugated dendritic peptidomimetic was also similar to Pro/Arg-conjugated system and the corresponding ITC result was consistent with the data obtained from the pull-down assay. The thermodynamic parameters of the peptidomimetics were quite different from those of the dynamin peptide. Both the changes in enthalpy $(\Delta H)$ and entropy $(\Delta S)$ of the peptidomimetics were positive, whereas those of the dynamin peptide were negative. These data may suggest that the binding of the peptidomimetic and dynamin peptide to amphiphysin II SH3 domain were driven by entropy and enthalpy, respectively. It is possible that the proton exchange exerted an influence on $\Delta H$ because the dendritic peptidomimetics have multiple amino groups in their backbone that could be protonated. ${ }^{32} \Delta S$ was estimated from the equation, $\Delta G=\mathrm{RT} \ln \left(1 / K_{\mathrm{d}}\right)=\Delta H-\mathrm{T} \Delta S$, where $\Delta G, \mathrm{R}$ and $\mathrm{T}$ are the Gibbs free energy, gas constant and temperature, respectively. Thus, $\Delta S$ may also be affected by the protonation. The detailed binding properties of the dendron-based peptidomimetics require further investigation. Furthermore, improvement to enhance the binding affinity and suppress nonspecific binding is necessary because the low binding affinity of these compounds limited any detailed analysis.

\section{CONCLUSIONS}

We have successfully designed and synthesized a novel type of peptidomimetic, which is a dendron that conjugates amino acids at the periphery. This protocol is capable of producing a diversity of library members by a one-cycle reaction. The amino-acid ratios of the peptidomimetic correlated well with the corresponding reaction ratios, indicating that the amino-acid component was controllable, allowing for the rational design of peptidomimetics. The peptidomimetic containing Pro and Arg was bound to the amphiphysin II SH3 domain with a similar level of affinity to a Pro-rich peptide of dynamin, although the binding manner might be different. The polymer backbone and terminal groups of the peptidomimetics need to be further improved to apply this kind of dendritic compound as a peptidomimetic.

\section{ACKNOWLEDGEMENTS}

We thank Dr Atsushi Harada (Osaka Prefecture University) for his help with the PAMAM dendron synthesis and Professor Hisataka Sabe and Dr Hajime Yano (Osaka Bioscience Institute) for their help with protein preparation. This work was supported by Grants from the Iketani Science and Technology Foundation and in part by Special Coordination Funds for Promoting Science and Technology of MEXT (Improvement of Research Environment for Young Researchers (FY 2008-2012)).
1 Falciani, C., Lozzi, L., Pini, A. \& Bracci, L. Bioactive peptides from libraries. Chem. Biol. 12, 417-426 (2005).

2 Gentilucci, L., Tolomelli, A. \& Squassabia, F. Peptides and peptidomimetics in medicine, surgery and biotechnology. Curr. Med. Chem. 13, 2449-2466 (2006).

3 Lam, K. C., Salmon, S. E., Hersh, E. M., Hruby, V. J., Kazmierski, W. M. \& Knapp, R. J. A new type of synthetic peptide library for identifying ligand-binding activity. Nature 354, 82-84 (1991).

4 Olson, G. L., Bolin, D. R., Bonner, M. P., Bos, M., Cook, C. M., Fry, D. C., Graves, B. J., Hatada, M., Hill, D. E., Kahn, M., Madison, V. S., Rusiecki, V. K., Sarabu, R., Sepinwall, J., Vincent, G. P. \& Voss, M. E. Concepts and progress in the development of peptide mimetics. J. Med. Chem. 36, 3039-3049 (1993).

5 Pastor, M. T., Mora, P., Ferrer-Montiel, A. \& Perez-Paya, E. Design of bioactive and structurally well-defined peptides from conformationally restricted libraries. Biopolymers 76, 357-365 (2004).

6 Bosman, A. W., Janssen, H. M. \& Meijer, E. W. About dendrimers: structure, physical properties, and applications. Chem. Rev. 99, 1665-1688 (1999).

7 Crespo, L., Sanclimens, G., Pons, M., Giralt, E., Royo, M. \& Albericio, F. Peptide and amide bond-containing dendrimers. Chem. Rev. 105, 1663-1681 (2005).

8 Astruc, D., Boisselier, E. \& Ornelas, C. Dendrimers designed for functions: from physical, photophysical, and supramolecular properties to applications in sensing, catalysis, molecular electronics, photonics, and nanomedicine. Chem. Rev. 110, 1857-1959 (2010).

9 Kojima, C. Design of stimuli-responsive dendrimers. Exp. Opin. Drug Delivery 7, 307-319 (2010).

10 Medina, S. H. \& El-Sayed, M. E. H. Dendrimers as carriers for delivery of chemotherapeutic agents. Chem. Rev. 109, 3141-3157 (2009).

11 Tekade, R. K., Kumar, P. V. \& Jain, N. K. Dendrimers in oncology: an expanding horizon. Chem. Rev. 109, 49-87 (2009).

12 Mintzer, M. A. \& Grinstaff, M. W. Biomedical applications of dendrimers: a tutorial. Chem. Soc. Rev. 40, 173-190 (2011).

13 Cheng, Y., Zhao, L., Li, Y. \& Xu, T. Design of biocompatible dendrimers for cancer diagnosis and therapy: current status and future perspectives. Chem. Soc. Rev. 40, 2673-2703 (2011).

14 Sadler, K. \& Tam, J. P. Peptide dendrimers: applications and synthesis. J. Biotechnol. 90, 195-229 (2002).

15 Helms, B., van Baal, I., Merkx, M. \& Meijer, E. W. Site-specific protein and peptide immobilization on a biosensor surface via pulsed native chemical ligation. Chem. Bio. Chem. 8, 1790-1794 (2007).

16 Roy, R., Baek, M. -G. \& Rittenhouse-Olson, K. Synthesis of $N, N^{\prime}$-Bis(acrylamido)acetic acid-based T-antigen glycodendrimers and their mouse monoclonal IgG antibody binding properties. J. Am. Chem. Soc. 123, 1809-1816 (2001).

17 Chabre, Y. M. \& Roy, R. Recent trends in glycodendrimer syntheses and applications. Curr. Top. Med. Chem. 8, 1237-1285 (2008).

18 Darbre, T. \& Reymond, J. L. Glycopeptide dendrimers for biomedical applications. Curr. Top. Med. Chem. 8, 1286-1293 (2008).

19 Majoros, I. J., Thomas, T. P., Mehta, C. B. \& Baker, Jr J. R. PAMAM dendrimer-based multifunctional engineered synthetic nanoscale bioconjugates for cancer therapy. J. Med. Chem. 48, 5892-5899 (2005).

20 Kinberger, G. A., Cai, W. \& Goodman, M. Collagen mimetic dendrimers. J. Am. Chem. Soc. 124, 15162-15163 (2002).

21 Kinberger, G. A., Taulane, J. P. \& Goodman, M. The design, synthesis, and characterization of a PAMAM-based triple helical collagen mimetic dendrimer. Tetrahedron 62, 5280-5286 (2006).

22 Kojima, C., Tsumura, S., Harada, A. \& Kono, K. A collagen-mimic dendrimer capable of controlled release. J. Am. Chem. Soc. 131, 6052-6053 (2009).

23 Suehiro, T., Tada, T., Waku, T., Tanaka, N., Hongo, C., Yamamoto, S., Nakahira, A. \& Kojima, C. Temperature-dependent higher order structures of the (Pro-Pro-Gly) ${ }_{10}$ modified dendrimer. Biopolymers 95, 270-277 (2011).

24 Kojima, C., Suehiro, T., Tada, T., Sakamoto, Y., Waku, T. \& Tanaka, N. Preparation of heat-induced artificial collagen gels based on collagen-mimetic dendrimers. Soft Matter 7, 8991-8997 (2011).

25 Owen, D. J., Wigge, P., Vallis, Y., Moore, J. D. A., Evans, P. R. \& McMahon, H. T. Crystal structure of the amphiphysin-2 $\mathrm{SH} 3$ domain and its role in the prevention of dynamin ring formation. EMBO J. 17, 5273-5285 (1998).

26 Wigge, P. \& McMahon, H. T. The amphiphysin family and their role in endocytosis at the synapse. Trends Neurosci. 21, 339-344 (1998).

27 Kojima, C., Hashimoto, A., Yabuta, I., Hirose, M., Hashimoto, S., Kanaho, Y. Sumimoto, H., Ikegami, T. \& Sabe, H. Regulation of Bin1 SH3 domain binding by phosphoinositides. EMBO J. 23, 4413-4422 (2004).

28 Harada, A., Kawamura, M., Matsuo, T., Takahashi, T. \& Kono, K. Synthesis and characterization of head-tail type polycation block copolymer as non-viral gene vector. Bioconjugate Chem. 17, 3-5 (2006).

29 Tono, Y., Kojima, C., Haba, Y., Takahashi, T., Harada, A., Yagi, S. \& Kono, K. Thermosensitive properties of poly(amidoamine) dendrimers with peripheral phenylalanine residues. Langmuir 22, 4920-4922 (2006).

30 Kiso, Y., Satomi, M., Ukawa, K. \& Akita, T. Efficient deprotection of $N^{G}$-tosylarginine with a thioanisole-trifluoromethanesulphonic acid system. J. Chem. Soc. Chem. Commun. 1063-1064 (1980).

31 Wiseman, T., Williston, S., Brandts, J. F. \& Lin, L. N. Rapid measurement of binding constants and heats of binding using a new titration calorimeter. Anal. Biochem. 179, 131-137 (1989).

32 Fukada, H. \& Takahashi, K. Enthalpy and heat capacity changes for the proton dissociation of various buffer components in $0.1 \mathrm{M}$ potassium chloride. Proteins 33, 159-166 (1998). 